\title{
Incorporating hydromorphology in strategic approaches to managing flows for salmonids
}

\author{
M. NEWSON \\ Tyne Rivers Trust, Hexham, UK \\ D. SEAR \\ School of Geography, University of Southampton, Highfield, Southampton, UK
}

\section{SOULSBY}

Northern Rivers Institute, Aberdeen University, Aberdeen, UK

\begin{abstract}
Whilst flow is often seen simplistically as a measurable and manageable variable in rivers, the habitat value of flow is delivered by interactions with channel morphology and substrate. The resulting hydromorphology impacts on all salmonid life stages; its proper understanding requires integration between the sciences of hydrology/hydraulics, geomorphology and freshwater ecology, but this integration is scarce. This study describes those features of river channel morphology and dynamics that are most relevant to hydromorphological status, describes progress in field assessment and outlines practical progress in calibrating in-channel habitat condition as an aid to setting flows. However, the incorporation of the true spatial and temporal variability of hydromorphology awaits further refinement of survey techniques and the long-awaited interdisciplinary research on causal process links. Meanwhile, amongst the geomorphological tools available to those setting environmental flows are fluvial audits, the definition and mapping of meso-scale biotopes and the use of realistic river typologies for the local application of general flow rules.
\end{abstract}

KEYWORDS: biotopes, fluvial audit, hydromorphology, patch dynamics, siltation, survey.

\section{Introduction: the rise of physical habitat (hydromorphology) in river management}

The River Tyne in north-east England illustrates the last 50 years of improvement in gross salmonid habitat; its recovery from being (according to official surveys) almost bereft of salmon, to becoming England's biggest salmon fishery, is normally credited to the massive improvement in chemical water quality throughout the catchment but notably in the estuary (Archer 2003).

The generally successful regulatory framework for point sources of industrial/sewage pollution means that the Tyne's history is paralleled throughout the UK but, as one limit on freshwater ecosystem health is tackled, another comes to prominence: morphology and flow, combined as hydromorphology, are now recognised as prime ecological limits by European legislation. Despite the goal of integrated catchment management, the contributing elements of fluvial integrity, recognised in the term hydromorphology, are normally managed separately. In the 1990s, fluvial geomorphology appeared on the river management radar as the result of the widespread view that land drainage since the 1930s has emasculated the diversity of forms and features that would appear in natural channels in England and Wales (Brookes 1988; Raven et al. 1998; Sear et al. 2010). A diverse river restoration movement was born, and official policies moved increasingly towards protection for remaining highquality physical habitat. Rivers entered the remit of both government and non-government conservation bodies, with fishery organisations, were prominent amongst the latter group. 


\section{Salmonid physical habitat}

Salmonids require a range of physical habitat types to produce viable numbers of returning adults to continue the population. Critical habitats within the freshwater phase include the following:

- Good-quality spawning habitat providing substrate, cover and flow depths to support the construction and persistence of redds, within which the supply of oxygen and removal of wastes are maintained within a thermal regime that promotes and sustains development of incubating embryos, and where alevins are able to escape to nursery areas.

- Good-quality nursery and rearing habitat providing food, flow and thermal regimes sufficient to sustain growth with space to accommodate competition and sufficient cover to avoid predation.

- Smoltification and adult migration require access to and from the sea from rearing habitats that are within the energetic budget of individual animals. These include availability of deeper water habitats to regulate thermal regime and cover to avoid predation and to provide rest.

- Pattern (patches) of critical habitats (within the distances of movement of individual life stages).

- Refugia at all stages to permit survival during disturbance (floods, drought, pollution events, thermal maxima, predation).

In addition, these habitats need to be in sufficient volume (not area because all are 3-dimensional features dependent on flow and substrate depths) to support a viable population. All of these aspects are impacted by morphological form, dimension and process, by the connectivity of the channel sediment system and by the connectivity of the channel and its catchment, for both flows and sediments (Tetzlaff et al. 2007; Sear 2011). It may be the complexity of these inter-relationships, which has, to date, frustrated the incorporation of hydromorphology in the setting of environmental flows.

\section{Key hydromorphological features of salmonid habitat}

A substantial and growing body of evidence, both conceptual and empirical, exists to link the availability of salmon habitats with particular geomorphological units and, in turn, with catchment scale processes of sediment transport and supply (Montgomery et al. 1999; Sear 2011). Traditionally, just a few morphological features have configured the way fisheries protection and restoration are approached. The early days of concerns over physical habitat and its restoration can be characterised as riffles and pools. As Keller (1976) put it, following his earlier fundamental study of the riffle-pool sequence (Keller \& Melhorn 1973), 'designing modified channels to have areas at which flow converges and diverges is consistent with our premise of designing with nature'. However, restored riffles were often static morphological mimic features with an ecological impact restricted to flow diversity within the limits of the site (Sear \& Newson 2004).

Montgomery et al. (1999) identified critical habitats with specific meso-scale geomorphic units, and Moir et al. (2004) applied the approach to a Scottish stream. Spawning activity is strongly associated with rifflepool morphologies, but in chalk streams, where coarse sediment transport is localised or absent, pool-riffle sequences are rare and spawning occurs in lowerenergy habitat patches such as glides or even pools (Sear et al. 2009; Sear 2011). In higher-energy systems, salmon can use small patches of gravel in step-pool morphologies whilst Buffington et al. (2004) demonstrated preferential selection of geomorphic units by different species. Every salmon life stage is associated with a dynamic (largely) riffle-pool bed morphology, because this combination of geomorphic unit provides a wide range of habitat patches (Emery et al. 2003) and connectivity between units is strong, allowing movement of fish between them.

\section{Geomorphological features and flow: essential integration for habitat quantity and quality}

Flows and geomorphology interact to create the dynamic living conditions within the flow column over both short and long time periods. In launching its Water Framework Directive, or WFD (EC 2000), the European Commission offered, as the basic physical habitat metric, hydromorphology (Newson \& Large 2006). The term is defined as 'the hydrological characteristics of rivers together with the physical structure they create'. In turn, this is a reflexive relationship as the structure created can influence the hydrological characteristics (e.g. floods, sediment yields) and the hydraulic characteristics that impact on local habitats. There is a need for a dynamic, process-based approach, and geomorphologists have long found the meso-scale (reach to biotope) as most suited to experimental understanding of dynamics and thus the development of flow management predictive tools.

Attempts at integration to make hydromorphology a reality are in their infancy. The research scales precious to the component sciences do not overlay well, a possible explanation for the underlying lack of interdisciplinarity (Vaughan et al. 2009), despite the 


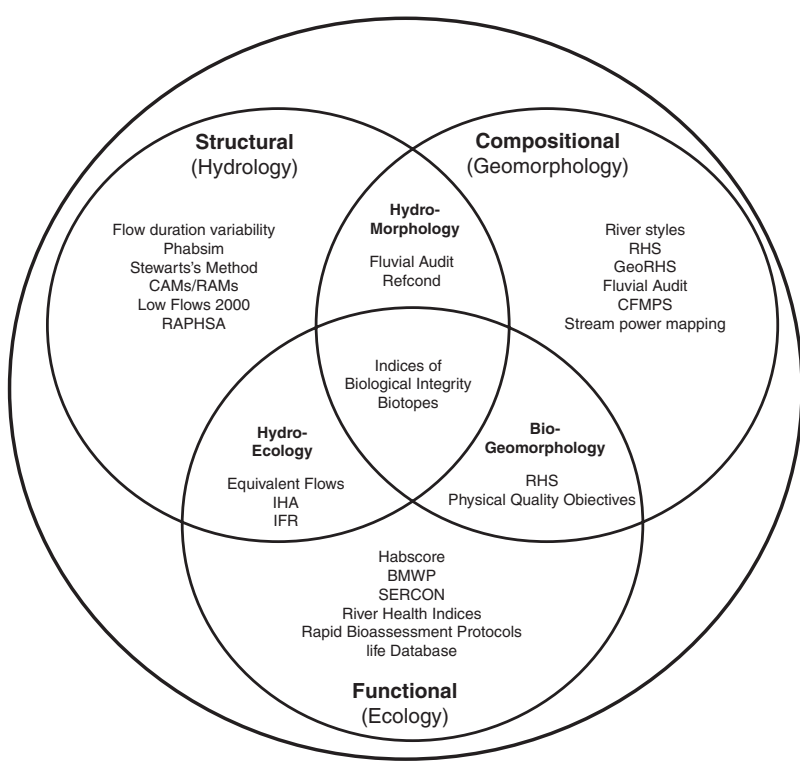

Figure 1. Structural, compositional and functional components of 'hydromorphology', and the component tools and typologies brought to the interdisciplinary interface by hydrology, geomorphology and ecology (after Kilsby et al. 2006).

attention now being drawn to the gaps between hydrology, geomorphology and ecology (Heritage et al. 2001).

The quest for appropriate interdisciplinary levels of assessment, restoration and monitoring linked to the drivers of physical habitat has proved difficult (see the review and Fig. 1 by Kilsby et al. 2006; also see Orr et al. 2008). Orr and Walsh (2007) tried to derive an integrated typological metric, appropriate to hydrology, geomorphology and ecology, with the added bonus that its driver (process) variables include those sensitive to climate change. At present, its worth has been validated in only one catchment - the Eden in Cumbria - but early indications are that it has significance for strategic fisheries habitat restoration, in that one Eden channel type dominates in terms of fry abundance. This is the sort of approach that is proving valuable overseas where reservoir development is continuing, but which is limited in the UK to academic post hoc impact assessments.

\section{Hydromorphology and environmental flows: current evidence for (dynamic) habitat significance and relevance to water resource systems design}

Hydromorphology requires an integrated evidence base. An important series of hydro-ecological studies concerning the empirical relationship between benthic biota and various components of flow regime has focussed on the potential of hydrological measures to index conditions of disturbance and refuge on the stream bed. Clausen and Biggs (1997a) selected the frequency of flood flows greater than three times the median flow as having the best relationship with periphyton and invertebrate density and diversity in New Zealand. Later, these authors recommended use of a basket of flow variables as predictors (Clausen \& Biggs 1997b) and added indices of bed stability (armouring) and nutrient concentrations (Clausen \& Biggs 1998). Studies in New Zealand have also attempted to use flow and sediment size indices as a more direct predictor of substrate stability (Duncan \& Biggs 1998; Biggs et al. 2000) in an attempt to elucidate the critical balance between the twin physical necessities of benthic life: disturbance and refugia (Townsend \& Hildrew 1994).

Converting the evidence base for the significance of hydromorphology to the habitat of the flow column to usable tools for flow setting faces the task of bringing together experimental data from a wide range of conditions, gathered for a wide range of purposes, many of them academic/theoretical. Five critical components of the environmental flow regime are illuminated by Poff et al. (1997): magnitude, frequency, duration, timing and rate of change. However, the master variable that these authors identify for driving geomorphological change is simplistic: bankfull discharge. Bankfull discharge is also called channel-forming discharge because energy delivery to the bed and banks peaks; higher flows can, however, be more geomorphologically effective in landscape terms (Newson 1980). All five elements of flow regime are reflexive in relation to the sediment system over different timescales. Within the flood flow range, bankfull discharge seems too static a marker: impacts on fisheries seem unpredictably divided between ecologically damaging and formative disturbances over a wide range of high river flows (Nislow et al. 2002a,b). For rivers regulated by impoundments, flushing flows are required, specifically designed to remove silts and sands deposited during the periods when direct supply for human consumption or irrigation dominates the use of the river (Newson et al. 2002). More recently, the US Nature Conservancy has developed indicators of hydrological alteration (Richter et al. 1997), which uses five groups of a total of 32 flow variables to calibrate the changes to flow regime caused by damming. The Richter approach has been modified for use in the UK, particularly to support interpretations of the WFD for rivers in Scotland affected by hydropower generation (Black et al. 2002). Flow regime pulses, their duration and flow reversals, are features of the methodology, 
which, however, uses expert empiricism to define weighting factors for a scoring system of impacts.

In the UK, $70 \%$ of gauged rivers show artificial influences on annual discharge but because the humid, temperate climate emphasises seasonal regimes, the most recent academic attempt to develop natural flows has focussed on regimes (Monk et al. 2006) and their climatic drivers (Harris et al. 2000).

None of these methodologies fully incorporates a quantified statement of hydromorphology: the geomorphological interaction with flow, either as an independent variable or as a variable itself impacted by formative floods. This is not the only problem; vitally important aspects of ecosystem integrity remain ignored; the hyporheic zone and exposed riverine sediments are sadly neglected by the in-channel research focus (Fig. 2). This imbalance has been partly addressed for salmonids by Malcolm et al. (2008) and Environment Agency (2009).

A simple approach to reconciling the hydrological and morphological dimensions of habitat quality is the adoption of meso-scale units like biotopes (Newson \& Newson 2000). These appear to relate morphology to flow (although not comprehensively) and have a proven influence on biota (Rowntree \& Wadeson 1998). Proponents of IFIM (Instream Flow Incremental Methodology) have accepted a need to incorporate the meso-scale detail of habitat quality within the habitat quantity objective of earlier models (see manuscript edited by Paraseiwicz 2007). Biotope mapping yields a series of general pictures of the flow controls exercised by substrate relative roughness, riffle-pool sequences (and their coarser counterparts), bar features and channel gradient. Biotope maps, com-

(a)

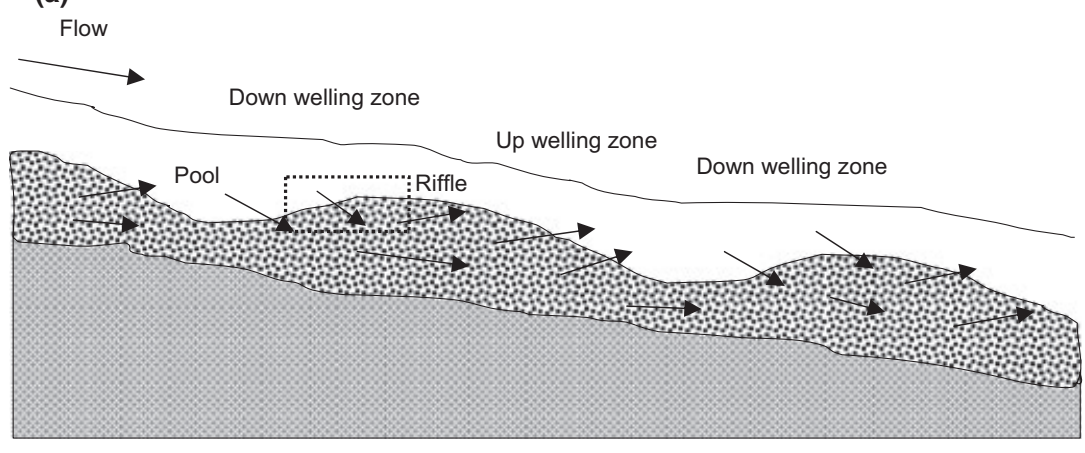

(b) Down welling zone Up welling zone

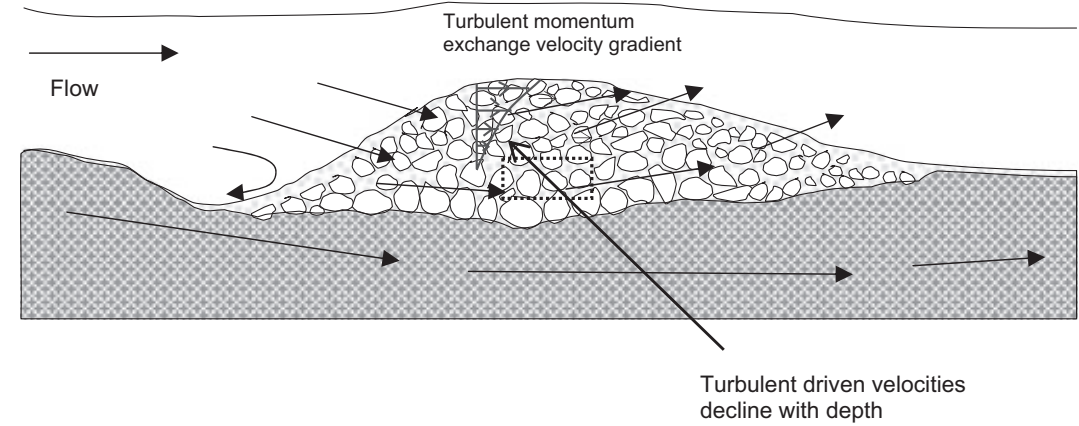

(c)

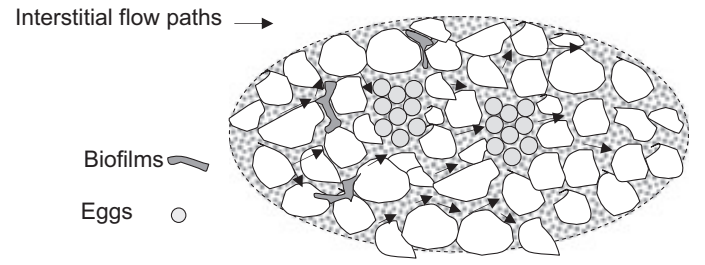

Figure 2. Sectional (a), (b - detail) and plan (c) views to illustrate the location and dynamics of flows in the hyporheic zone of a gravel-bed river. Groundwater supplies are also important to hyporheic flows in appropriate geologies. 
bined with the salient physical properties of the channel and the frequency of flow pulses of critical discharges, can yield a dynamic insight into hydromorphological conditions, sufficient to provide guidance on anthropogenic impacts and shed some light on potential habitat links (Padmore 1998).

\section{Hydromorphology - natural channels to carry environmental flows?}

There is no doubt that the riffle-pool sequence is still a central preoccupation of those managing habitat integrity for Atlantic salmon, Salmo salar L., and many other fish. Manipulations of both flow regime and sediment supply/entrainment processes (largely by dams) need, in the UK, to be retrospectively adjusted from maximised water supply/power generation benefits to an optimum for the stream ecosystem and human needs (see the detailed study of North Tyne riffle dynamics below Kielder Dam by Sear 1992, 1993; Sear 1996). Hanrahan (2007) perpetuated the fascination with the riffle-pool sequence for rivers in the Pacific Northwest region of the USA, developing, with some precision, where salmon will spawn in relation to the spatial sequence of riffles and pools. Buffington et al. (2004) linked the availability of spawning gravels to the channel hydraulic process and to sediment supply. Nevertheless, this step towards fluvial hydrosystem capability is heavily constrained by local physiographic factors and geomorphologists should ground-truth by walkover or remote surveys, as opposed to assuming universal sets of features.

It should be noted at the outset that geomorphological data are not collected outside academia in the UK, with the partial exception of River Habitat Surveys (RHS) (Raven et al. 1998). This represents a major discrepancy in terms of tools for setting environmental flows, considering the very dense hydrometric network employed to yield flow data. However, as hydromorphological tools and data arrive on the scene, compensation flows and flow regulation targets historically set solely from the extensive flow database need to be re-evaluated on the basis of a much broader information base, albeit at varying degrees of uncertainty.

In the UK, demand for hydromorphological data has projected activities towards primary surveys for geomorphological features, meso-scale habitat units and/or calibration data for ecohydraulic approaches. Morphological elements of known significance to habitat (drawn from a Salmon Action Plan) include (Babtie, Brown \& Root, 2004) sediment substrate, morphological diversity, river continuity and boundary conditions.

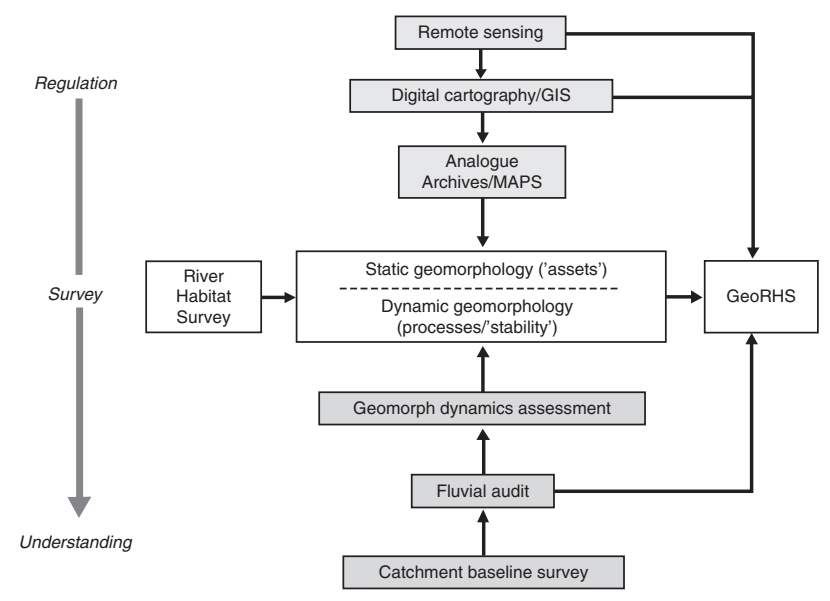

Figure 3. Available survey/assessment tools in fluvial geomorphology (after Sear et al. 2010); the tools are arranged in order of the detail they provide (top to bottom) and their accompanying value for evidencebased decisions.

The application of Fluvial Audits to Salmon Action Plan surveys represents a choice from a suite of available assessment techniques, reviewed in the 'Guidebook of Applied Fluvial Geomorphology' (Sear et al. 2010). Figure 3 indicates the relationship between these approaches.

The extensive (shallow) coverage of hydromorphological variables available from the Environment Agency's RHS permits a simple, survey-based, sitespecific framework for assessing physical habitat (e.g. under the Habitats Directive or the WFD) using a scoring system described by Walker et al. (2002). This scheme uses reference conditions for river habitat, selected by experts, to set up points scoring protocols for the presence of positive features (habitat quality) and the impact of anthropogenic intrusions (habitat modification). Paradoxically, however, there is no mention of flow!

The RHS approach does not particularise geomorphological features for individual channel management decisions, let alone flow management strategies. For the River Till in Northumberland, UK, a set of operational geomorphological criteria relevant to salmon habitats was derived from habitat guidance (Hendry \& Cragg-Hine 2003). A decision matrix was constructed to rate the impact of a variety of potential river and riparian developments (but not dams!) at the site of the feature, upstream of it and through the short-to-medium time period (Newson \& Orr 2004). In a southern England, lowland example - the River Wensum - where a bigger ecosystem picture was required, Fluvial Audit data were used to assess the naturalness of geomorphologically scaled river reaches 


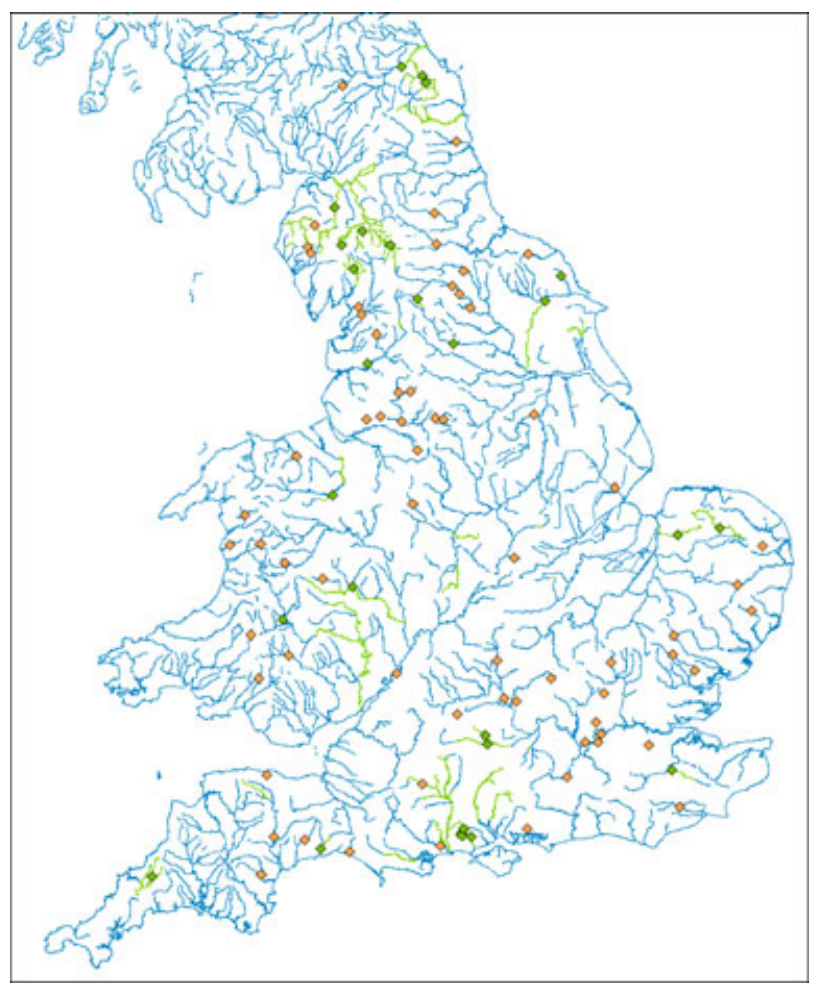

Figure 4. Location of known Fluvial Audit data in Britain (GeoData Institute, Southampton University 2007).

before a Multi-Criteria Assessment carried options to stakeholders. The core assessment technique for the Wensum, extended to other river sites of special scientific interest (SSSIs), was again Fluvial Audit (Sear et al. 2008, 2009), whose application has now reached a considerable coverage (Fig. 4). Fluvial Audit is river-specific, time-consuming and therefore expensive; it is highly likely that, for retro-fitting existing water resource or hydro-power schemes in the UK with an environmental flow regime (assuming the scheme can vary its releases) broader-brush, remotely sensed schema are required as tools.

\section{Catchment geomorphological influences: towards flushing flows?}

The catchment scale will be vital for protecting spawning gravels against the ingress of fine sediments, commonly now labelled in England and Wales as the siltation problem (see Naden et al. 2002; Smith et al. 2003; Kemp et al. 2011). It appears that changed farming techniques, both in the arable and in livestock sectors, together with some climate trends, are making more fine sediments available to the catchment sediment system. In regulated rivers, the low-flow regime is critical in the deposition of these sediments. The problem summarises the dilemmas faced by developers of basin-scale hydromorphological tools. Whilst more fine sediments are released from the farmed land surface, their route to a river is critically affected by local conditions of field size, slope, boundaries and drainage. There may be localised hot spots of sediment yield to rivers, but they cannot be specified without a combination of Fluvial Audit and measurements of sediment flux (Newson 2010). Local specificity can in part be addressed by sensitively structured models of erosion, transport and deposition, but doubt remains about the fate of the fines in creating (or not) a siltation problem in channel habitat terms. As part of an urgent need to set up precautionary regulatory tools for say Natura 2000 salmon rivers, there is an engaging debate about the suitability of information transfer (as standards of sediment yields for whole catchments, e.g. Walling et al. 2005) or field survey techniques for individual problem cases (e.g. Newson et al. 2005). In some cases, and to protect other siltsensitive species such as the freshwater pearl mussel, Margaritifera margaritifera (L.), it seems unlikely that reservoir operators will be prepared to release flushing flows to freshen riffle gravels and move on the contained silt. Conservation options then involve gravel cleansing (jetting - whilst the tradition was ploughing the river bed) and channel narrowing to give the regulated low flows sufficient velocity to transport fine sediments away from sensitive bed habitat sites.

\section{Incorporating complexity/uncertainty in space and time}

\section{Habitat patches}

The structure of in-channel habitats is increasingly characterised both physically and in relation to ecological and biological processes, in terms of discrete patches. The habitat patch concept recognises that inchannel habitat is composed of a spatial pattern of discrete habitats of differing size, shape, persistence and, vitally, sensitivity to flow regime. Habitat patches can be defined in terms of single factors (e.g. substrate Armitage \& Cannan 1998), combinations of factors (e.g. zones of similar depth, velocity or Froude number Newson \& Newson 2000), geomorphological units (e.g. channel typologies Montgomery \& Buffington 1997) and biotic communities (e.g. vegetation patches). The boundaries between these patches may not be sharp, but represent gradients of change in environmental variables. 
The now familiar hierarchical habitat model of rivers (Frissell et al. 1986) recognises a mosaic of riverine habitat patches across five scales, with each scale providing a different definition of habitat with the catchment as one end member and the microhabitat at the other: this concept is vital to the way forward for environmental flows. Explicit within such hierarchical models of river habitats is the interdependence of one scale on another. Thus, the suite of microhabitats found in a chalk stream catchment will be different to those found in an upland catchment - a further constraint on a one size fits all approach to the hydromorphological input to defining a flow regime and a challenge to existing simplistic river typologies. However, the precise arrangement and extent of different meso-habitats within two hydrologically similar catchments will differ according to segment scale landscape structure and, in most UK rivers, the catchment-specific history of land and river management. These contexts are vital to the setting of environmental flows; in the UK, they are now normally applied post hoc to reservoirs constructed in the purple patch for engineered water resources, and channel management at the end of the last century has perhaps contributed to the current serious lag between international flow setting practice and those in the UK.

\section{Channel dynamics}

A major attribute of in-channel habitat relevant to salmonids is its dynamism. Natural channel habitats are dynamic over a range of timescales in response to variable frequency events. The relationships between fluvial disturbances, ecosystem patch structures and biodiversity have been recognised as fundamental principles in running water ecology (Ward et al. 2002). The association of habitat patches with geomorphic and hydraulic patterns that change according to fluxes of large wood, sediment and water results in shifting habitat mosaics (SHM) (Stanford et al. 2005). None of these principles and none of the hydromorphological evidence are yet incorporated in flow management practices in the UK (Sear 2011).

Most models of species-habitat relationships have treated habitat as a static constraint (Wimberley 2006). The SHM model of riverine habitats explicitly links habitat patchiness (the mosaic) to dynamic natural processes. The SHM model recognises four scales of connectivity within the river - longitudinal connectivity of different habitat segments within a catchment; lateral connectivity between the river and floodplain driven by processes of flooding and re-working; vertical connectivity between the surface water and hyporheic zone; and a temporal dimension that defines the dynamics across these spatial scales. The SHM model arises from the interaction of dynamic physical and biological processes, resulting in the creation of different habitat mosaics that change over time (Stanford et al. 2005). Accordingly, in a natural ecosystem, small areas may fluctuate widely over time because of disturbances, but on a broader spatial scale, the proportions of different patch types and connectivity will remain constant. A characteristic of this model is that habitat succession and regeneration creates a habitat mosaic with largely stable habitat age distributions; thus, one specification of high ecological status in water bodies for salmonids is a reach where processes function to create and maintain critical habitats important to salmonids over long periods of time (e.g. $100+$ year). In the UK, the urgency of the WFD demands has meant that the longer term, slow progression of morphological pressures, has been ignored.

The frequency of disturbances and the habitats associated with the presence of dominant disturbance types help to create and maintain particular suites of habitat patches in a channel reach (Montgomery \& Buffington 1997). Disturbances are also the origin of habitat change. The intermediate disturbance hypothesis of channel habitats identified maximum biodiversity with intermediate level of habitat disturbance and turnover. Higher-frequency disturbance results in dominance of rapid colonising communities, whilst low rates of disturbance allow long-term selective competition resulting in dominance of a few key species. In the case of salmonids, disturbance frequency relates to the timescale of life stage occupancy of a given habitat. Thus, for good incubation survival, the frequency of spawning habitat scour or siltation must not lead to persistently poor recruitment.

\section{Conclusions}

Montgomery's (2004) view is that 'In order to be most effective, the contribution of geomorphological insights to salmon recovery efforts requires both assessment protocols commensurate with providing adequate knowledge of context, and experienced practitioners well versed in adapting general theory to local settings'. The UK remains short of assessment protocols for the simple reason that capital investment in new reservoirs has not been made and policies have worked against new dams: no R\&D finance has been available. If a new era in which new water resources development schemes are planned because of climate change and, to comply with the WFD, and existing 
'Highly Modified Rivers' with a healthier flow regime are modified, there is a need to extrapolate beyond research catchments and reaches therein. It is vital that the power of remote sensing approaches to the calibration of habitat quality and the impacts of current flow management be explored as a matter of urgency.

Some legislatures, e.g. Scotland, feel confident in using hydromorphological quality to check the impacts of individual development proposals, which may impact flow regime or morphology, in the way that has become widespread in the UK during implementation of the EU Habitats Directive regulations. This has required the development of a regulatory morphological impact assessment metric - MImAS - based on an existing channel typology (Greig et al. 2006). MImAS is a reasonable expression of the least uncertain knowledge in hydromorphology; however, a detailed research and development wish list to extend and refine such tools would include the following:

- Improving methods to quantify in-channel habitat to predict the use and selection of habitat by salmonids across their different life stages;

- Recognition that natural habitats are dynamic spatially and temporally;

- Gaining an understanding of habitat creation and maintenance over longer timescales and how these timescales relate to viable populations of salmonids;

- Improving understanding of how salmonids select and use habitats within pristine and modified conditions incorporating the presence of other animals. What is the significance of how the habitat is spatially organised?

- Coordinating the translation of knowledge into practical management tools (improved methods of quantifying habitat resource, selection and utilisation) perhaps via the creation of decision support tools for fisheries managers;

- Creating and sustaining a viable funding stream to undertake the science and dissemination;

- Critically assessing existing management activities against scientifically robust targets: a review of existing flow agreements and strategic models designed for the future, proved against the past.

\section{References}

Archer D. (2003) Tyne and Tide. A Celebration of the River Tyne, Ovingham, Northumberland: Daryan Press, $270 \mathrm{pp}$. Armitage P.D. \& Cannan C.E. (1998) Nested multiscale surveys in lotic systems - tools for management. In: G. Bretschko \& N. Helesic (eds) Advances in River Bottom Ecology. Leiden: Backhuis, pp. 293-314.
Babtie, Brown and Root Ltd (2004) Catchment Geomorphology Action Plan: the River Esk Catchment. Leeds: Environment Agency, 115 pp.

Biggs B.J.F., Duncan M.J., Suren A.M. \& Holomuzki J.R. (2000) The importance of bed sediment stability to benthic ecosystems of streams. In: M.P. Mosley (ed.) Gravel-Bed Rivers $V$. Wellington: New Zealand Hydrological Society, pp. 423-449.

Black A.R., Bragg O.M., Duck R.W. \& Rowan J.S. (2002) Development of a method to assess ecological impact due to hydrological regime alteration of Scottish rivers. International Association of Hydrological Sciences 276, 45-51.

Brookes A. (1988) River Channelization: Perspectives for Environmental Management, Chichester: Wiley, 215 pp.

Buffington J.M., Montgomery D.R. \& Greenberg H.M. (2004) Basin-scale availability of salmonid spawning gravel as influenced by channel type and hydraulic roughness in mountain catchments. Canadian Journal of Fisheries and Aquatic Sciences 61, 2085-2096.

Clausen B. \& Biggs B.J.F. (1997a) Relations between benthic biota and hydrological indices in New Zealand streams. Freshwater Biology 38, 327-342.

Clausen B. \& Biggs B.J.F. (1997b) Flow variables for ecological studies in New Zealand rivers. Proceedings 24th Hydrology and Water Resources Symposium. Wellington: New Zealand Hydrological Society, pp. 101-108.

Clausen B. \& Biggs B.J.F. (1998) Streamflow variability indices for riverine environmental studies. In: $\mathrm{H}$. Wheater \& C. Kirby (eds) Hydrology in a Changing Environment, Vol. 1. Wallingford: British Hydrological Society, pp. 357364.

Duncan M.J. \& Biggs B.J.F. (1998) Substrate stability vs. flood frequency and its ecological implications for headwater streams. In: H. Wheater \& C. Kirby (eds) Hydrology in a Changing Environment. Wallingford: British Hydrological Society, pp. 347-355.

Emery J.C., Gurnell A.M., Clifford N.J., Petts G.E. \& Soar P.S. (2003) Classifying the performance of riffle-pool bedforms for habitat assessment and river rehabilitation design. River Research and Applications 19, 533-549.

Environment Agency (2009) The Hyporheic Handbook: A Handbook on the Groundwater-Surface Water Interface and Hyporheic Zone for Environment Managers. Science report: SC050070. Bristol: Environment Agency, 264 pp.

European Commission (2000) Directive 2000/60/EC of the European Parliament and of the Council of 23rd October 2000: establishing a framework for Community action in the field of water policy. Official Journal of the European Communities: Brussels; 22.12.2000, L327, 1-72.

Frissell C.A., Liss W.J., Warren C.E. \& Hurley M.D. (1986) A hierarchical framework for stream habitat classification. Viewing streams in a watershed context. Environmental Management 10, 199-214. 
Greig S.M., Richardson R. \& Gibson J. (2006) A New Iimpact Aassessment Tool to Support River Engineering Regulatory Decisions. Technical Report. Project No. WFD49. Edinburgh: Scottish Environmental Protection Agency, $26 \mathrm{pp}$.

Hanrahan T.P. (2007) Bedform morphology of salmon spawning areas in a large gravel-bed river. Geomorphology 86, 529-536.

Harris N.M., Gurnell A.M., Hannah D.M. \& Petts G.E. (2000) Classification of river regimes: a context for hydroecology. Hydrological Processes 14, 2831-2848.

Hendry K. \& Cragg-Hine D. (2003) Ecology of the Atlantic Salmon: Salmo salar. Conserving Natura 2000 Rivers, Ecology Series 7. Peterborough: English Nature, 36 pp.

Heritage G.L., Charlton M.E. \& O'Regan S. (2001) Morphological classification of fluvial environments: an investigation into the continuum of channel types. Journal of Geology 109, 21-33.

Keller E.A. (1976) Channelization: environmental, geomorphic and engineering aspects. In: D.R. Coates (ed.) Geomorphology and Engineering. Stroudsburg, PA: Dowden, Hutchinson and Ross, pp. 115-140.

Keller E.A. \& Melhorn W.N. (1973) Bedforms and fluvial processes in alluvial stream channels: selected observations. In: M. Morisawa (ed.) Fluvial Geomorphology. Binghampton, NY: State University of New York, pp. 253-284.

Kemp P., Sear D.A., Collins A.L., Naden P.S. \& Jones J.I. (2011) The impacts of fine sediment on riverine fish. Hydrological Processes 25, 1800-1821.

Kilsby C., Large A.R.G., Newson M.D., Orr H.G. \& Walsh C.L. (2006) Incorporating Climate Change in River Typologies for the Water Framework Directive. Science Project Record SC030301. Bristol: Environment Agency, $92 \mathrm{pp}$.

Malcolm I.A., Grieg S., Youngson A.F. \& Soulsby C. (2008) Hyporheic influences on salmon embryo survival and performance. In: D.A. Sear \& P. deVries (eds) Salmon Spawning Habitat: Physical Controls, Biological Responses and Approaches to Remediation, Vol. 65. Bethesda, MD: American Fisheries Society Symposium, pp. 225-248.

Moir H.J., Gibbins C.N., Soulsby C. \& Webb J. (2004) Linking catchment geomorphic characteristics to the spatial pattern of discharge use by spawning salmon in two Scottish upland streams. Geomorphology 60, 21-35.

Monk W.A., Wood P.J., Hannah D.M., Wilson D.A., Extence C.A. \& Chadd R.P. (2006) Flow variability and macroinvertebrate community response within riverine systems. River Research and Applications 22, 595-615.

Montgomery D.R. (2004) Geology, geomorphology, and the restoration ecology of salmon. GSA Today, 14, 4-12.

Montgomery D.R. \& Buffington J.M. (1997) Channel-reach morphology in mountain drainage basins. Geological Society of America Bulletin 109, 596-611.
Montgomery D.R., Pess G., Beamer E.M. \& Quinn T.P. (1999) Channel type and salmonid spawning distributions and abundance. Canadian Journal of Fisheries and Aquatic Science 56, 377-387.

Naden P., Smith B., Jarvie H., Llewellyn N., Matthiessen P., Dawson H. et al. (2002) Life in UK Rivers. Methods for the Assessment and Monitoring of Siltation in SAC Rivers. Part 1: Summary of Available Techniques. Wallingford: Centre for Ecology and Hydrology, $133 \mathrm{pp}$.

Newson M.D. (1980) The geomorphological effectiveness of floods. A contribution stimulated by two recent events in mid-Wales. Earth Surface Processes 5, 1-16.

Newson M.D. (2010) Understanding 'hot-spot' problems in catchments: the need for scale-sensitive measures and mechanisms to secure effective solutions for river management and conservation. Aquatic Conservation: Marine and Freshwater Ecosystems 20(S1), S62-S72.

Newson M.D. \& Large A.R.G. (2006) 'Natural' rivers, 'hydromorphological quality' and river restoration: a challenging new agenda for applied fluvial geomorphology. Earth Surface Processes and Landforms 31, 16061624.

Newson M.D. \& Newson C.L. (2000) Geomorphology, ecology and river channel habitat: mesoscale approaches to basin-scale challenges. Progress in Physical Geography 24, 195-217.

Newson M.D. \& Orr H.G. (2004) Tools for Applying the EU habitats Directive for the English River Tweed cSAC: Hydromorphological Study of the River Till. Northeast Region, Newcastle upon Tyne: Newcastle University for Environment Agency, 54 pp.

Newson M.D., Pitlick J. \& Sear D.A. (2002) Running water: fluvial geomorphology and river restoration. In: M.R. Perrow \& A.J. Davy (eds) Handbook of Ecological Restoration, Vol. 1. Cambridge: Cambridge University Press, pp. 133-152.

Newson M.D., Sear D.A. \& Orr H.G. (2005) Sediment Inputs to Freshwater Ecosystems: Towards Regulatory Approaches at the Catchment Scale; Are 'Critical Yield' Philosophies Currently Practicable? Report to Exeter University under English Nature Contract EIT35-05-019 2005.

Nislow K.H., Magilligan F.J., Fassnacht H., Bechtel D. \& Ruesink A. (2002a) Effects of hydrologic alteration on the flood regime of natural floodplain communities in the Upper Connecticut River basin. Journal of the American Water Resources Association 38, 1533-1548.

Nislow K.H., Magilligan F.J., Folt C.L. \& Kennedy B.P. (2002b) Within-basin variation in the short-term effects of a major flood on stream fishes and invertebrates. Journal of Freshwater Ecology 17, 305-317.

Orr H.G., Large A.R.G., Newson M.D. \& Walsh C.L. (2008) A predictive typology for characterising hydromorphology. Geomorphology 100, 32-40. 
Padmore C.L. (1998) The role of physical biotopes in determining the conservation status and flow requirements of British rivers. Aquatic Ecosystem Health and Management 1, 25-35.

Paraseiwicz P. (2007) The mesoHABSIM model revisited. River Research and Applications, 23, 893-903.

Poff N.L., Allan J.D., Bain M.B., Karr J.R., Prestegaard K.L., Richter B.D. et al. (1997) The natural flow regime. A paradigm for river conservation and restoration. BioScience 47, 769-784.

Raven P.J., Holmes N.T.H., Dawson F.H., Everard M., Fozzard I. \& Rouen K.J. (1998) River Habitat Quality. The Physical Character of Rivers and Streams in the United Kingdom and Isle of Man. River Habitat Survey Report 2. Bristol: Environment Agency, 84 pp.

Richter B.D., Baumgartner J.V., Wigington R. \& Braun D.P. (1997) How much water does a river need? Freshwater Biology 37, 231-249.

Rowntree K.M. \& Wadeson R.A. (1998) A geomorphological framework for the assessment of instream flow requirements. Aquatic Ecosystem Health and Management 1, 125 141.

Sear D.A. (1992) The effects of river regulation for hydroelectric power on sediment transport and flow dynamics in riffle/pool sequences. In: R.D. Hey, P. Billi, C.R. Thorne \& P. Tacconi (eds) Dynamics of Gravel Bed Rivers. Chichester: Wiley, pp. 327-342.

Sear D.A. (1993) Fine sediment infiltration into gravel spawning beds within a regulated river experiencing floods: ecological implications for salmonids. Regulated Rivers: Research and Management 8, 373-390.

Sear D.A. (1996) Sediment transport processes in pool-riffle sequences. Earth Surface Processes and Landforms 21, 241262.

Sear D.A. (2011) Integrating science and practice for the sustainable management of in-channel salmonid habitat. In: P. Kemp (ed.) Salmon Habitat Management. Chichester: Wiley, pp. 81-111.

Sear D.A. \& Newson M.D. (2004) The hydraulic impact and performance of a lowland rehabilitation scheme based on pool-riffle installation: the River Waveney, Scole, Suffolk, UK. River Research and Applications 20, 847-863.

Sear D.A., Hill C.T. \& Downes R.H.E. (2008) Geomorphological Assessment of Riverine SSSIs for the Strategic
Planning of Physical Restoration. Natural England Research Report NERR013. Sheffield: Natural England, $82 \mathrm{pp}$.

Sear D.A., Hill C.T., Newson M.D., Emery J. \& Branson J. (2009) A method for applying fluvial geomorphology in support of catchment-scale river restoration planning. Aquatic Conservation: Marine and Freshwater Ecosystems 19, 506-519.

Sear D.A., Newson M.D. \& Thorne C.R. (2010) Guidebook of Applied Fluvial Geomorphology. London: Thomas Telford, $257 \mathrm{pp}$.

Smith B., Naden P. \& Cooper D. (2003) Siltation in Rivers. 3. Integrated Assessment Procedure. Conserving Natura 2000 Rivers, Conservation Techniques Series. Peterborough: English Nature, $51 \mathrm{pp}$.

Stanford J.A., Lorang M.S. \& Hauer F.R. (2005) The shifting habitat mosaic of river ecosystems. Verhandlungen des Internationalen Verein Limnologie 29, 123-136.

Tetzlaff D., Soulsby C., Bacon P.J., Youngson A.F., Gibbins C.N. \& Malcolm I.A. (2007) Connectivity between landscapes and riverscapes: a unifying theme in integrating hydrology and ecology in catchment science. Hydrological Processes 21, 1385-1389.

Townsend C.R. \& Hildrew A.G. (1994) Species traits in relation to a habitat templet for river systems. Freshwater Biology 31, 265-275.

Vaughan I.P., Diamond M., Gurnell A.M., Hall K.A., Jenkins A., Milner N.J. et al. (2009) Integrating ecology with hydromorphology: a priority for river science and management. Aquatic Conservation 19, 113-125.

Walker J., Diamond M. \& Naura M. (2002) The development of physical quality objectives for rivers in England and Wales. Aquatic Conservation: Marine and Freshwater Ecosystems 12, 381-390.

Walling D., Webb B. \& Shanaxhan J. (2005) Investigations into the Use of Critical Catchment Yields for Assessing and Managing Fine Sediment Inputs into Aquatic Ecosystems. University of Exeter. English Nature Contract No. EIT3505-019, 109 pp.

Ward J.V., Tockner K., Arscott D.B. \& Claret C. (2002) Riverine landscape diversity. Freshwater Biology 47, 517539.

Wimberley M.C. (2006) Species dynamics in disturbed landscapes: when does a shifting habitat mosaic enhance connectivity? Landscape Ecology 21, 35-46. 